\title{
CAPITALISMO IMOBILIÁRIO E FINANCEIRO E IMPLICAÇÕES SOCIAIS DA PRODUÇÃO HABITACIONAL EM BARCELONA
}

\author{
real estate and financial capitalism and the social \\ implications of housing production in Barcelona
}

Danilo Volochko*

\begin{abstract}
Resumo
A análise da metrópole de Barcelona nos ajuda a compor a problemática da financeirização da produção do espaço que vem ocorrendo nos últimos anos em diversos países, entre eles o Brasil. Tal processo se apresenta no mundo com ritmos e intensidades distintas, pois conta com diferentes mediações históricas, político-institucionais, econômicas, ideológicas e sociais entre os países de economia avançada e aqueles chamados em desenvolvimento. Neste sentido, é importante considerar o modo como este processo ocorre num país como a Espanha, que apoiou seu grande crescimento econômico da última década nos fundamentos da produção imobiliária do espaço sob um capitalismo financeirizado. É possível identificar as contradições presentes naquele país em torno da realização dos negócios imobiliários - a valorização crescente do solo urbano - e os embates postos pela apropriação do espaço urbano para a moradia, que revelam a luta contra a expropriação financeira e imobiliária dos habitantes mais pobres ou sobreendividados. Este caminho pode nos auxiliar na interpretação da produção mundializada do espaço, lida, no caso aqui tratado, por meio da expansão metropolitana periférica da produção da habitação em Barcelona, que nos coloca diante de uma crise não apenas econômica mas sobretudo de uma crise social mais ampla.
\end{abstract}

Palavras-chave: Financeirização, Produção do espaço, Metropolização, Habitação, Barcelona, Lutas.

\begin{abstract}
The analysis of the metropolis of Barcelona allow us to deal with the process of financialization of the production of space that has been occurring in recent years in several countries, including Brazil. This process has different rhythms and intensities around the world, as it faces different historical, political-institutional, ideological and social arrangements among advanced economies countries and the so-called developing countries. In these sense, it is important to consider the way this process take place in a country like Spain, which supported its high economic growth in the last decade in the property development which produces space under a financial capitalism. It is possible to identify the contradictions within the property development in that country - the rising value of urban land - and the conflicts posed by the use of the space for living, which reveal the struggle against real state and financial expropriation of the poorest or over-indebted people. This analysis can help us interpreting the globalized production of space, taken, in the case treated in this article, through the extend of the housing projects for the outskirts of the metropolis of Barcelona, which confront us with a crisis that is not only economic but a wider social crisis.
\end{abstract}

Key words: Financialization, Production of space, Housing, Metropolization, Barcelona, Struggles.

\begin{abstract}
Resumen
El análisis de la metrópoli de Barcelona nos ayuda a tomar el tema de la financiarización de la producción del espacio que ha venido ocurriendo en los últimos años en varios países, incluso en Brasil. Este proceso se presenta en el mundo con distintos ritmos e intensidades, ya que cuenta con diferentes mediaciones históricas, políticas, institucionales, económicas, ideológicas y sociales entre los países de economías avanzadas y aquellos llamados en desarrollo. En este sentido, es importante considerar el modo como ocurre este proceso en un país como España, que sustentó su gran crecimiento económico de la última década en las bases de la producción inmobiliaria del espacio bajo un capitalismo financiarizado. Es posible identificar en este país las contradicciones acerca de la realización de los negocios inmobiliarios - lo incremento del valor del suelo urbano - y los conflictos planteados por la apropiación del espacio urbano para la vida de la gente, lo que revela la lucha contra la expropiación financiera y inmobiliaria de los hogares más pobres o sobreendeudados. Este camino nos puede ayudar en la interpretación de la producción globalizada del espacio, en el caso aquí planteada a través de la expansión metropolitana y periférica de la producción de la vivienda en Barcelona, lo que nos pone frente a una crisis no sólo económica sino más bien una gran crisis social.
\end{abstract}

Palabras clave: Financiarización, Producción del espacio, Vivienda, Metropolización, Barcelona, Luchas.

(*) Dr. em Geografia Humana pela Universidade de São Paulo - Av. Rouxinol, 431, CEP: 04516-000, São Paulo (SP), Brasil, Tel.: (+55 11)953839869-dvolochko@usp.br 


\section{INTRODUÇÃO}

A análise das dinâmicas espaciais recentes da metrópole de Barcelona não pode negligenciar o fato de que a urbanização naquele país produziu uma história urbana bastante distinta da nossa, que poderia facilmente recuar à Antiguidade, com o domínio do Império Romano sobre a Península Ibérica e sobre os povos aí presentes. O processo milenar de adensamento urbano nas cidades ibéricas - que antecedem mesmo a Espanha como Estado Nacional - produziu, de modo geral, cidades compactas, amuralhadas, com uma enorme população urbana vivendo concentrada em pequenos espaços, estabelecendo relações específicas com o campo e com os espaços circunvizinhos, geralmente pequenas cidades, portanto produziu uma morfologia urbana com características próprias. Uma primeira ressalva a ser feita é que a urbanização na Espanha não produziu - não nas mesmas dimensões como no Brasil - uma urbanização formal e ao mesmo tempo uma urbanização - completamente associada à primeira - dita informal/ilegal: as imensas periferias constituídas por favelas e autoconstruções. Com isso não estamos dizendo que não se constituem espaços centrais e espaços periféricos nas cidades espanholas, mas chamamos a atenção para o fato de que as hierarquizações socioespaciais são, naquele país, menos gritantes e dramáticas que aquelas vividas no Brasil. Estas desigualdades sociais em nosso país certamente acusam uma herança histórica colonial profundamente assentada no trabalho escravo, numa atividade econômica voltada para o mercado externo, numa concentração da riqueza nas mãos dos donos das terras, privatizadas em 1850.

Mas não se trata, neste artigo, de identificar essas diferenças históricas, e sim de tentar identificar, no momento atual da urbanização espanhola e particularmente da metrópole de Barcelona, elementos de uma lógica espacial bastante atual da reprodução do capitalismo que não se limita ao caso estudado mas pode ser verificada - com as devidas diferenciações - em outros países, sejam eles desenvolvidos ou não. Portanto, nesta análise, se busca aprofundar a compreensão dos mecanismos particulares de atuação dos níveis econômico, político e social no contexto da reestruturação recente da produção habitacional na metrópole barcelonesa como possibilidade de localizar continuidades, descontinuidades, diferenças, aproximações e relações entre o processo financeiro global que atravessa Brasil e Espanha, e com isso esboçar a construção de uma visão de conjunto sobre os espaços metropolitanos a partir da problemática da produção e apropriação da habitação. Com efeito, se há diferenciações históricas significativas que envolvem a constituição das metrópoles nos diversos países - e elas existem -, também é verdade que existem tendências totalizantes de reprodução lógica da dinâmica capitalista, que busca se territorializar produzindo novas configurações dos espaços metropolitanos em muitos países.

\section{ESPAÇOS METROPOLITANOS E METROPOLIZAÇÃO: o caso de Barcelona}

Alguns autores, entre eles Robira (2005), entendem os territórios metropolitanos como territórios "adormecidos" ou mais propriamente como territórios "reserva" para o processo de acumulação espacial do capital, que oportunamente convoca tais territórios a cumprir um ajuste do espaço urbano às necessidades da acumulação territorial. Também é importante ressaltar que, de acordo com Lefebvre (2008, pp.117-118), é o setor imobiliário que tende a ascender a um plano central a partir de determinado momento, e que seria necessário "mostrar como e porque o capitalismo apossou-se do solo". Esse autor escreve que "o imobiliário (produção e especulação) oscila entre uma função subordinada de retomada econômica, uma função diversionista, uma função de regulação, uma função dominante. De acordo com os momentos, os países, etc.” (LEFEBVRE, 2008, p.118). Estas ideias sinalizam a importância dos movimentos de mobilização do espaço e de sua produção no desenvolvimento do modo de produção capitalista, produzindo uma urbanização que se constitui desigualmente conforme os países e regiões, sendo que, no caso aqui analisado, a metropolização imobiliária em andamento se coloca como um dos horizontes reprodutivos do capitalismo não apenas espanhol, como veremos, mas também do capitalismo brasileiro, como apontaremos. 
Sobre o processo de metropolização, Robira (2005, p.17) adverte que os "espaços marginais (...) não merecem esse qualificativo porque se localizam nos limites ou nas margens do tecido urbano, mas porque (...) são espaços, do ponto de vista urbano e social, não-regulares (...)". A autora assevera ainda, apoiada nas formulações de Harvey (2004), que os espaços marginais "constituem os territórios-reserva onde se produz a acumulação da escassez". No caso, por exemplo, do espaço metropolitano e periférico de São Paulo, a escassez de habitações consideradas "formais" e a concentração de espaços pouco valorizados ou desvalorizados o constituem enquanto espaço que abriga uma espécie de "matéria-prima" abundante a ser explorada pelo setor imobiliário avançado: terrenos desvalorizados que vão se constituindo como possibilidade para uma nova "habitação popular de mercado", que se expande construindo nas (e valorizando as) periferias. Não vem ao caso, aqui, detalhar este novo mercado, sendo importante reter que este processo se realiza também no bojo de um processo de metropolização do espaço (cf. termo de LENCIONI, 2003), que tem que ver com uma reprodução da metrópole que evidencia uma transcendência do processo de urbanização ao expandir os conteúdos, lógicas e características próprias da metrópole para um espaço mais vasto, seja as periferias metropolitanas, seja uma região inteira que se metropoliza. Para aquela autora, a metropolização do espaço se colocaria como uma força de determinação do urbano contemporâneo.

$\mathrm{Na}$ Espanha, a expansão metropolitana alicerçada na promoção privada de um grande parque habitacional conheceu notável explosão que durou 10 anos (1998 a 2008), ancorada na ampliação dos créditos hipotecários e pela estabilidade da economia. Mas este fenômeno se desenvolveu também especulativamente - alguns autores o qualificam como borbuja inmobiliaria - resultando, num primeiro momento, numa superoferta de habitações novas em áreas metropolitanas que foi acompanhada por uma grande subida dos preços que emanava das áreas centrais. Segundo dados do Institut d'Estadística de Catalunya, o preço médio do metro quadrado de um imóvel novo no município de Barcelona passou, apenas de 2004 a 2007, de 4.193,00€ para 5.918,00€. Embora de modo distinto, os preços de habitações novas na conurbação de Barcelona e em outros municípios daquela província apresentaram elevações consideráveis, acentuando as dificuldades de acesso à moradia e precarizando as condições de vida. A partir de 2007 a crise financeira internacional repercute na contração geral do crédito e atinge severamente o setor imobiliário espanhol, ocasionando enorme queda na venda de imóveis novos, quebra de empresas construtoras e desemprego no setor .

Diante das novas determinações econômicas, sociais, políticas e espaciais próprias da passagem de um regime de produção conhecido como fordista para aquele de uma acumulação flexível - a partir da década de 1970 na Europa -, é possível identificar o modo como essa mudança no padrão de acumulação está definindo mudanças quanto a forma de produção do espaço metropolitano? Fundamentalmente, o processo imobiliário-financeiro no âmago do processo global de metropolização do espaço revela que o sentido do solo urbano para a valorização capitalista ganha novos propósitos na medida em que o solo urbano metropolitano transcenderia sua qualidade de reserva de valor para integrar circuitos imobiliário-financeiros ativos de valorização. Tais circuitos alavancam o setor imobiliário avançado no caso da metrópole de São Paulo, capacitando-o, embora de modo instável, a elevar a escala de produção de imóveis residenciais (mercado popular ou econômico) e assim ampliar sua base social. No caso espanhol, a valorização desenfreada do solo caminhou pari passu com uma enorme metropolização residencial dada pela oferta habitacional, que redundaria, depois de 2008, numa restrição do acesso à moradia, já veremos por que.

$\mathrm{Na}$ Catalunha, a constituição metropolitana das principais cidades da comarca do Vallès Occidental, entre elas tomamos como exemplo Sabadell e Terrassa, esteve ligada a um forte protagonismo industrial associado ao dinamismo da própria capital Barcelona, sendo que essa região recebeu, até a crise de 2007, inversões imobiliárias que atestam um duplo processo: de um lado, o esgotamento do solo edificável para novas construções habitacionais em Barcelona, e de outro a expulsão da população da capital devido à subida dos preços - em 2007 o preço médio do m2 em Sabadell-Terrassa era de 3.800,00€ contra quase 6.000,00 € em Barcelona. O aumento demográfico 
e os deslocamentos populacionais facilitados pela construção de importantes eixos viários e ferroviários entre Barcelona e Sabadell-Terrassa fizeram com que essas cidades fossem identificadas como cidades-dormitório, mas que parecem ter sido "despertadas" pela disponibilidade de solo que gerou até muito recentemente uma intensa atividade de construção habitacional. Já a cidade de Sant Cugat del Vallès, que integra a conurbação barcelonesa imediata, caracteriza-se, distintamente, como uma área de forte valorização fundiária destinada a abrigar populações mais abastadas. Neste sentido, recebe grandes aportes das principais construtoras espanholas e catalãs, como Metrovacesa e Inmobiliaria Colonial, constituindo-se como uma das pontas do processo especulativo que fez disparar os preços até o ponto de congestionar o estoque habitacional. Estes espaços e processos permitem que se trace um perfil analítico do espaço metropolitano de Barcelona em sua articulação com as dinâmicas de reestruturação econômica, particularmente imobiliária.

As características daqueles espaços metropolitanos, Sabadell, por exemplo, nos permitem avaliar transformações em sua paisagem e morfologia. Sua situação no contexto metropolitano, sua reduzida distância em relação a Barcelona, a rede de transporte (ferroviária e rodoviária) ali instalada, atesta a presença de alguns galpões e edifícios que testemunham a atividade industrial, que contrastam com os novos estabelecimentos comerciais voltados à venda de mobiliário residencial, com as novas construções de prédios de apartamentos residenciais que muitas vezes conferem um aspecto "desértico" nas áreas de expansão, possuidoras de infraestruturas e equipamentos urbanos - parques, calçadas, asfaltamento das vias, iluminação - instalados em meio às quadras ainda sem edificar. As características urbanísticas e arquitetônicas dos novos edifícios se misturam com os polígonos de viviendas compostos por blocos de edifícios similares, prédios de "proteção oficial" (habitações de promoção pública), entre outros elementos.

A metropolização e a valorização do solo em Barcelona é estudada por autores, entre eles Busquets (2004), que apontam para o processo de dispersão do sistema metropolitano barcelonês atual articulando-o às relações cotidianas de residência, trabalho e serviços e lembrando que até 1970 havia um forte protagonismo da indústria neste processo. Este autor adverte haver um grande consumo de solo e escreve que o elevado papel do mercado de terras exigiria medidas de controle contra o que ele chama de mais-valias especulativas que se apossam das reabilitações urbanas. Capel (2009) e ainda outros autores como Borja (2009), Font (2007), Muñoz (2007), Nello (2007) e Indovina (2007) também discutem a metropolização e a questão da cidade compacta versus a cidade dispersa em seus livros e artigos, levantando questões relevantes e ressaltando a importância do planejamento urbanístico e das políticas de gestão territorial para a contenção desse processo de dispersão em baixa densidade dos tecidos metropolitanos. Porém, não se perguntam: qual é o novo papel desempenhado pelo espaço quando se fala em dispersão? Que papel o espaço joga nesse processo para além do plano da localização e da forma? É possível pensar em termos de espaços mais ou menos urbanizados?

Parte significativa dos autores espanhóis trata apenas tangencialmente a relação entre o preço do solo e o chamado processo de dispersão; apresentam com isso um tom de conciliação e de regulamentação, via planejamento, dos processos capitalistas ligados à dinâmica urbana. Em direção mais crítica, as ideias de Robira (2004) e Benach (2004) consideram o planejamento urbano um importante fator de produção do espaço, que articula ideologias - acadêmicas, política, de imagens e símbolos culturais - às práticas - aqueles que intervêm, técnicos, arquitetos, administradores etc. - voltando suas análises para a centralidade do plano do social, da cotidianidade, do uso do espaço da cidade pelos seus habitantes. Considero que esta linha de investigação se distancia de uma fé apressada no Planejamento Estratégico e propõe um exame crítico dos seus limites e das suas possibilidades para a população barcelonesa, conhecedora de um Planejamento Estratégico que, como escreve Arantes (2002), se coloca como um modelo que agrega novos ícones arquitetônicos (arquitetos mundialmente reconhecidos) ao espaço urbano conjugados a grandes eventos internacionais (Exposições Universais, Olimpíadas, Fóruns de Cultura), e que vão realizando um 
city marketing ligado à requalificações, instalações de novos equipamentos, construção de praças etc., sempre levando a assinatura e o design moderno como instrumentos de aquisição de vantagens numa rede mundial de competição entre cidades. Acima de tudo, a crítica a ser feita joga luz no avesso da espetacularização dessas cidades, na homogeneização, fragmentação e hierarquização do espaço a que vem se prestando os processos de renovação urbana fomentados em grande medida pelo mesmo Planejamento Estratégico. É de se notar a contundência da crítica de Delgado (2007) sobre a "mentira e a fraude" do modelo Barcelona, que promove, entre outros processos, a turistificação daquela cidade.

A história urbana e metropolitana de Barcelona e seus desdobramentos socioespaciais contemporâneos são tratados por Sánchez (2009), que escreve que a formação da Região Metropolitana de Barcelona (RMB) se assenta em uma estrutura urbana pré-existente e consolidada há muito (meados do século XIX) e na rede de transporte que se inicia em 1967 (com as "carreteras" e "autopistas"). O início do processo de metropolização, para este autor, data da década de 1950, e foi marcado por um processo de migração interna espanhola, que vai de 1939 a 1960, em que o papel dos assentamentos industriais vai ser importante. Assim, segundo Sánchez (2009), na RMB, até 1950, o crescimento das cidades do entorno de Barcelona não ocorre por desconcentração interna, mas pela expansão de cada cidade industrial através da recepção de migrantes da zona rural, de fora da região. Mais recentemente, escreve o autor, com a modernização da rede de transporte e o crescimento/conurbação/saturação do território da cidade central ocorre o duplo processo de destruição e relocalização da atividade industrial para o entorno metropolitano, que acompanha a mudança residencial das novas classes médias e também dos trabalhadores fabris.

A metropolização nas cidades da RMB é marcada por mudanças na estrutura de comercialização, seguindo as transformações na estrutura produtiva e no emprego, destacando-se a produção sob pedido e a venda de indústrias catalãs para empresas de capital internacional. Este processo expulsa de Barcelona zonas logísticas (redistribuição) e setores mais intensivos em tecnologia (escritórios, zonas de serviços, de lazer), seguindo as autopistas e permitindo, ao mesmo tempo, segundo Sánchez (2009), a abertura de espaços residenciais em áreas rurais que se metropolizam. Isto está relacionado, talvez principalmente segundo pensamos, ao encarecimento do valor do solo em Barcelona, que expulsa população e passa a implicar novas estruturas territoriais e novos processos socioespaciais que, como dizem alguns autores, tendem a aumentar a distância entre o lugar de trabalho e o lugar de residência. Tanto Sabadell como Sant Cugat del Vallès, para Sánchez (2009), representam um território expansivo em termos populacionais, cujas características são que quase a metade da população se desloca diariamente para outro município para trabalhar. Muñoz (2007, p. 63) escreve que na segunda coroa metropolitana de Barcelona, onde se encontram Sabadell e Sant Cugat del Vallès, entre 1993 e 1995 há uma consolidação das tendências de dispersão da moradia.

Segundo as ideias gerais de Robira, há uma relação importante segundo a qual até 1980 a localização da população estava ainda mais ou menos condicionada por uma relação entre a moradia e o lugar de trabalho, sendo que de 1980 para cá se tornou dominante a população se instalar apenas no lugar onde elas podem pagar para morar, já que o lugar de emprego não é fixo e as estruturas de transporte permitem a mobilidade. Então há uma "opção obrigada" de localização, que impõe o nexo do valor da moradia em primeiro lugar e apenas em segundo lugar a proximidade do trabalho. A autora escreve que há uma mescla de custos, trabalho e infraestruturas que direcionam os processos de localização na RMB aliados a certa estabilidade econômica, política e social adquirida até os anos 2000 que fez com que, por exemplo, os filhos dos operários da região pudessem ter acesso ao ensino superior. Outro dado que devemos adicionar é o fato de que, a partir dos anos 2000, a presença de imigrantes é uma constante não apenas em Barcelona, mas em toda a Catalunha e na Espanha de modo geral.

Sánchez (2009, p. 16) escreve que: 
O processo de urbanização envolvente abre a possibilidade de iniciar uma etapa de especulação, dado o aumento do valor do solo industrial ocupado ante a possibilidade de reconvertê-lo em solo residencial ou de serviços mais intensivo em capital (...). Ademais (...) coincidiu com um momento de elevação desmesurada do preço do solo e da atividade construtiva, com a bolha imobiliária que explodiu em 2008.

Este processo, que se realiza como metropolização no bojo de outros processos como a valorização fundiária, a reestruturação produtiva e os avanços da economia financeiro-imobiliária, vem constituindo, como refere Sánchez (2009), um processo triplo: expansão da cidade central / interação com os antigos assentamentos / expansão dos antigos núcleos maduros. O processo de metropolização implica uma nova produção do espaço econômico (de industrial à terciário), mas também do espaço residencial, portanto da vida cotidiana. Então o processo de rearranjo espacial da economia avançada - das requalificações urbanísticas voltadas ao turismo na área central, da melhoria das infraestruturas e equipamentos urbanos etc. - produz um rearranjo nos espaços metropolitanos, que passam a abrigar seja novas atividades industriais e econômicas seja uma nova população que se desloca para poder morar devido à pressão do preço dos imóveis nas áreas valorizadas. Há, segundo Robira, um imbricamento simultâneo entre a especulação do solo, a desindustrialização e as inversões em capital fixo (infraestruturas) que também e ao mesmo tempo estimulam a mobilidade. Mas há um fato: a moradia e o preço do solo tornam-se caros em todo o território metropolitano. Tal dinâmica do preço do solo em Barcelona e na Catalunha de modo geral apresenta-se da seguinte forma: elevações acentuadas e constantes até 2006, estabilização em 2007 e início de reduções em 2008 devido à crise.

\section{PROPRIEDADE PRIVADA DO SOLO E METROPOLIZAÇÃO: a financeirização e a (frágil) "sociedade de proprietários"}

É importante notar que o modelo imobiliário espanhol - que se colocou como base do crescimento econômico daquele país na última década -, privilegiou abertamente o regime de moradia em propriedade privada em relação ao regime de aluguel. As taxas de home ownership na Europa coletadas no sítio da Eurostat em 2010 - que medem a proporção de proprietários privados de seus imóveis frente aos imóveis totais dos países - apontam a Espanha como um dos países europeus com taxas mais elevadas: 82,1\% . Em países como a Espanha e os EUA, desenvolveu-se com alguma intensidade real e ideológica o que López Hernández \& Rodríguez López (2010) denominam uma "sociedade de proprietários", base de um consenso social fundamentado num tipo de capitalismo cuja financeirização teria levado, depois de um longo ciclo, à formação de uma ampla classe média proprietária (até bem recentemente). Esta sociedade de proprietários, realidade que se revelou mais ideológica que concreta, chegou a integrar por um período consideravelmente grande parte da população à propriedade privada do solo, através do crédito expandido. Houve, segundo os autores, uma identificação "propriedade imobiliária/família/classe média" nesta sociedade de proprietários (2010, p.467), que por muito tempo teria sustentado uma acumulação proletarizante, haja vista o mascaramento do empobrecimento social (dos direitos) pela sensação de consumo garantida pelo endividamento. Inclusive, isto gerou/tem gerado uma urbanização "dispersa" ou "difusa", como costuma-se denominá-la. Nos dizeres de López Hernández \& Rodríguez López (2010, p.438):

el triunfo de la 'propiedad' sobre cualquier pretensión socializante en la tenencia de vivienda, los usos del suelo y, en general, la producción urbana, no son sólo el producto de nuevas formas de experiencia urbana, constituyen también el principal factor en la constitución material de una nueva modalidad de ciudad. La masiva construcción de viviendas, el nuevo predominio de los modelos de la ciudad dispersa, la extensión del crédito y la dilatación de las desigualdades sociales (...) han tenido la suficiente potencia como para dibujar geografías sociales y ecológicas bastante distintas de la ciudad industrial clásica. 
Num processo anterior e de certa forma similar, Hall (2002) discute a formação dos subúrbios nos EUA, argumentando que o boom suburbano estava baseado em quatro pilares (HALL, 2002, pp. 344-345):

as novas estradas que penetravam por terras situadas fora do alcance do velho trólebus e do transporte de interligação sobre trilhos; o zoneamento dos usos do solo (...); as hipotecas, que, garantidas pelo governo, possibilitavam prazos longos e juros baixos absorvíveis pelas famílias de renda modesta; e a explosão de natalidade que ocasionou um súbito aumento na demanda de casas (...).

Mas esse autor ressalta que "suas casas estavam hipotecadas a gigantescas instituições financeiras; e sequer lhes ocorria constituírem-se uma sociedade de vigorosos e auto-suficientes proprietários" (HALL, 2002, p.344). As recentes crises nestes países, tornadas crise social e representadas pela elevação do desemprego, dilapidação dos direitos, etc., chegam a uma situação que, como veremos em Barcelona, aponta para uma expropriação financeira tornada imobiliária, na qual a propriedade privada do solo de muitos vai para as mãos dos credores das hipotecas.

Este processo de expansão do regime de construção visando a venda e a realização da propriedade privada dos imóveis se coloca a partir do momento em que a Espanha, ao entrar na democracia e na União Européia, conhece, segundo Naredo (2010), uma refundação oligárquica do poder, combinando um caciquismo imobiliário com o avanço de financiamentos baratos e abundantes. Este mesmo autor escreve que "en el modelo ejemplificado por España, el negocio inmobiliario se basa, sobre todo, en la posibilidad de añadir varios ceros al valor de los terrenos por el mero hecho de hacerlos urbanizables" (NAREDO, 2010). Chegou-se a um ponto em que, nos dizeres deste autor, "se desató la espiral propia de las burbujas especulativas, en las que se compra porque se piensa que los precios van a subir y los precios suben porque aumentan las compras cada vez más financiadas con créditos" (NAREDO, 2010). Isto sinaliza um processo geral de crise habitacional que fragiliza as frações médias e menos abastadas daquela sociedade ao encarecer o solo e as moradias destinadas às classes médias, ao que se soma processos como o desemprego e o sobreendividamento financeiro. A crise é uma crise habitacional face ao encarecimento da moradia e ao sobreendividamento das famílias impossibilitadas de pagar as cotas de suas hipotecas e ademais desprotegidas pela legislação espanhola, crise imobiliária, crise financeira, crise do trabalho, e porque não crise do Estado de Bem-Estar, quando este deixa de garantir os direitos básicos para o bem-estar da população.

Os caminhos da crise em Barcelona nos colocam diante da problemática da financeirização, da crise imobiliária e da moradia, e das plataformas sociais de resistência. Do ponto de vista da produção imobiliária, é interessante verificar mudanças de estratégia das grandes incorporadoras, como a Inmobiliaria Colonial - uma das maiores construtoras da Espanha - cujos investimentos, atravessados pela crise, se dirigem para novos espaços e novos negócios imobiliários. Neste sentido, a posição desta (e de outras) empresas imobiliárias frente à crise tem sido a de culpar os mercados financeiros por terem feito muita especulação com a habitação, como se eles próprios não tivessem arquitetado e se beneficiado disso também. Esta empresa está liquidando o desenvolvimento imobiliário no setor de produção residencial, passando por uma reestruturação na qual ela passar a investir apenas na compra e arrendamento de edifícios de escritórios nas zonas mais nobres de Madrid (Av. Castellana), Barcelona (Av. Diagonal) e em Paris (La Défense), focando seus novos negócios em atividades de gestão de ativos.

Martínez Peinado (2010), analisando a crise desde a perspectiva do processo de circulação do capital global, ressalta, citando outros autores (BRENNER, CHESNAIS, LAPAVITSAS, HARVEY) que o atual momento de financeirização hegemoniza o ciclo D-D' (puramente financeiro, distante da produção) que vem incorporando novos proletariados "fordistas periféricos", incluindo novos espaços periféricos ou semiperiféricos do mundo e ampliando (ou ao menos mantendo) as taxas de mais-valia. Portanto, não parece descartada a hipótese sobre a existência atual de deslocamentos dos investimentos financeiros globais (sobretudo aqueles provenientes dos países ricos, como EUA 
e Espanha, atingidos pela crise) em direção aos setores imobiliários de países da América Latina como Brasil, México, Argentina e Chile, ou a outros países dos chamados BRICS (Brasil, Rússia, Índia, China e África do Sul) em busca de melhores remunerações. Esta hipótese dialoga, em parte, com o debate sobre a internacionalização do setor imobiliário brasileiro, sendo que os investimentos estrangeiros nas grandes incorporadoras brasileiras, como de resto na Bovespa, pode indicar este movimento, como mostram as tabelas seguintes:

Tabela 1 - Participação dos investidores estrangeiros no volume total das distribuições realizadas na Bovespa - 2007 a 2011

\begin{tabular}{c|c}
\hline ANO & PARTICIPAÇÃO (\%) \\
\hline 2007 & $75,4 \%$ \\
\hline 2008 & $48,1 \%$ \\
\hline 2009 & $66,7 \%$ \\
\hline 2010 & $26,2 \%$ \\
\hline 2011 & $55,3 \%$
\end{tabular}

Fonte: http://www.bmfbovespa.com.br/home.aspx?idioma=pt-br Acesso em: 02/03/2012. Elaboração: Danilo Volochko.

Tabela 2 - Participação dos investidores estrangeiros em distribuições públicas de ações de incorporadoras brasileiras - 2007 a 2011. Volume estrangeiro na oferta total (part. \%)

\begin{tabular}{c|c|c|c|c}
\hline EMPRESA & $\mathbf{2 0 0 7}$ & $\mathbf{2 0 0 9}$ & $\mathbf{2 0 1 0}$ & $\mathbf{2 0 1 1}$ \\
\hline PDG & $93,4 \%$ & $\mathrm{~s} /$ distr. & $46,8 \%$ & $\mathrm{~s} / \mathrm{distr}$. \\
\hline Tecnisa & $68,3 \%$ & $\mathrm{~s} /$ distr. & $\mathrm{s} /$ distr. & $53,4 \%$ \\
\hline Gafisa & $93,1 \%$ & $\mathrm{~s} /$ distr. & $61,8 \%$ & $\mathrm{~s} / \mathrm{distr}$. \\
\hline Even & $52,5 \%$ & $\mathrm{~s} /$ distr. & $46,5 \%$ & $\mathrm{~s} / \mathrm{distr}$. \\
\hline Inpar & $69,6 \%$ & $\mathrm{~s} /$ distr. & $68,5 \%$ & $\mathrm{~s} / \mathrm{distr}$. \\
\hline MRV & $73,3 \%$ & $70,0 \%$ & $\mathrm{~s} /$ distr. & $\mathrm{s} / \mathrm{distr}$. \\
\hline Direcional & $\mathrm{s} /$ distr. & $64,3 \%$ & $\mathrm{~s} /$ distr. & $88,8 \%$
\end{tabular}

Fonte: http://www.bmfbovespa.com.br/home.aspx?idioma=pt-br Acesso em: 02/03/2012 Elaboração: Danilo Volochko.

Os dados sobre a participação dos investimentos estrangeiros nas incorporadoras brasileiras são dados aproximativos; a informação que se divulga sobre a posição acionária de tais empresas apenas explicita aqueles acionistas com mais de 5\% das ações, logo, muitos investidores (que detêm menos de 5\% das ações) ficam "escondidos". Entretanto, mesmo considerando apenas os acionistas principais (que detêm mais de 5\% das ações), em média os investidores estrangeiros participam com no mínimo $15 \%$ das ações das principais incorporadoras brasileiras, porcentagem que seguramente pode se elevar até $50 \%$ ou mais, dada a "invisibilidade" dos pequenos investidores e dadas às porcentagens elevadas do volume acionário adquirido por estes investidores estrangeiros quando da distribuição pública de ações dessas empresas.

\section{SOBREENDIVIDAMENTO: expropriações e resistências}

A outra ponta da financeirização, segue Martínez Peinado (2010), ocorreu através de um sobre-endividamento de empresas mas especialmente de pessoas para que o nível de consumo 
exigido fosse mantido. A captação massiva das rendas das populações ativas e não ativas implicou financeirizar as necessidades básicas, como a moradia. Na Espanha, este processo implicou um avanço das "Cajas de Ahorros", em uma espécie de "capitalismo popular que consiste en perforar derechos fundamentales (en este caso, el derecho a la vivienda) y convertirlos en fuentes de acumulación de riqueza (...) (Taller contra la Violencia Inmobiliaria y Urbanística, 2006, p.17)”. Neste importante trabalho coletivo, pode-se ler ainda que (Taller contra la Violencia Inmobiliaria y Urbanística, 2006, p.19:

la apuesta estratégica de los poderes políticos y económicos por la potenciación del mercado hipotecario y la mercantilización de la vivienda ha supuesto una nueva especie de acumulación primitiva con repercusiones en otros sectores de la economía. En este contexto cabe destacar que los beneficios y la influencia de La Caixa (...) han aumentado al ritmo del desmantelamiento del rudimentario Estado de Bienestar (...).

Por fim, o coletivo adverte que (Taller contra la Violencia Inmobiliaria y Urbanística, 2006, p.54):

estos procesos, que se explican en el marco de un ámbito urbano regulado desde una lógica de flujos económicos y en el que lo inmobiliario es tratado como un sector económico más, tienen como consecuencia la descomposición de los tejidos de sociabilidad, una permanente movilidad forzada que fomenta el aislamiento y la soledad, y la asunción de la incertidumbre y la precariedad como condiciones constituivas de nuestras vidas.

As atividades da Plataforma de Afectados por la Hipoteca (PAH) apontam o sentido deste coletivo para o enfrentamento social do processo em tela. A PAH é uma associação apartidária e gratuita que se propõe a realizar uma dupla tática: de um lado, reunir, ouvir e tentar assessorar (juridicamente, psicologicamente) pessoas e famílias que estão em uma situação de dívida hipotecária e em vias de perder sua casa; e de outro lado tenta formar um discurso e uma ação coletivos em torno do tema da habitação, da sua restituição como um direito social e humano prioritário e portanto de enfrentar sua inserção total na lógica do mercado imobiliário e financeiro. Além de reuniões e assembléias, a PAH traça estratégias de visibilização social do problema da moradia por meio de seu sítio na internet, de manifestações públicas, da concessão de entrevistas e reportagens para rádio e televisão, de reuniões de articulação com outros coletivos e movimentos sociais - associações de vizinhos, diretórios de estudantes, artistas, professores, entidades culturais, sindicatos, entre outros) além de campanhas como a STOP! Desahucios (Parem os Despejos!), que busca, para chamar a atenção da sociedade, frear efetivamente algumas execuções hipotecárias de famílias que acabam sendo despejadas de suas casas, numa ação de pressão popular.

Para se ter ideia da magnitude e da gravidade crescente do problema, o Consejo General del Poder Judicial traz os seguintes dados para as execuções hipotecárias em Barcelona: em 2007 foram apresentadas no total de 2.804 execuções; em 2008 foram 6.759 e em 2009 foram apresentadas no total 10.738 execuções hipotecárias. Na Espanha, esse número sobe para um total de 177.948 execuções hipotecárias de 2007 a 2009, sendo que, segundo dados da mesma fonte, apenas nos três primeiros trimestres de 2010 foram apresentadas no total 71.333 execuções no país, totalizando quase 250.000 execuções hipotecárias entre 2007 e o terceiro trimestre de 2010 . Tendo em vista essa situação, umas das principais frentes de atuação da PAH é a reivindicação de reformas institucionais/ legislativas para fazer efetivo o direito à moradia. Neste sentido, uma das medidas centrais exigidas pela PAH é a regulação da dación en pago, mecanismo jurídico que possibilita a liquidação total da dívida caso o banco execute a hipoteca e restitua o imóvel da família. Outras soluções exigidas pela PAH são: garantir que as pessoas afetadas pela hipoteca tenham acesso à justiça gratuita; garantir que ninguém fique na rua enquanto siga existindo milhões de imóveis vazios; converter o 
parque de moradias em processo de execução hipotecária em parque público de aluguel; realizar uma Auditoria social sobre o funcionamento do mercado hipotecário.

A PAH realiza uma luta de resistência contra os abusos do capital financeiro, não se tratando de uma luta contra o Estado. Desse modo, ao defender direitos como a moradia contra a lógica da propriedade enquanto mero valor de troca, a PAH se coloca diante de algumas contradições, já que combater os abusos do capital financeiro significa lutar para que o Estado esteja do lado da população. Além disso, percebo que a luta pelo direito à moradia pode absolutizar uma luta mais radical pelo "direito à cidade". Mas o interessante da ação da PAH é que ela contempla uma base social extraordinariamente ampla, quantitativamente e em termos de espectros de classes, desde imigrantes em situações mais precárias às classes médias, passando pelos setores inferiores dessa classe média. A disseminação financeira, o endividamento, abarca a todos, o que pulveriza e torna dispersa uma luta contra isto que nos abarca. Então o questionamento dos bancos, das hipotecas, das execuções hipotecárias que culminam em despejos acaba questionando o sentido do capital financeiro, da propriedade privada, e do capitalismo em geral.

\section{PENSANDO A ESPANHA E O BRASIL: algumas aproximações}

A situação abordada nos permite entrever as complexidades inerentes e as diferenças certamente existentes entre a Espanha e o Brasil, e mesmo nos aponta a dificuldade das comparações. Mas, observando os mecanismos da reprodução financeira e imobiliária espanhola, talvez seja possível pensarmos em termos de relações contraditórias reproduzidas dentro e fora desses espaços urbanos/ nacionais. Relações que reproduzem - guardando desigualdades históricas e diferenças diversas - a centralidade do espaço enquanto condição, meio e produto (cf. ideia de CARLOS, 2008) da totalização do processo econômico-político do capitalismo: sua financeirização global e as políticas locais ou nacionais que sustentam sua existência, suas crises e expansões. Neste sentido, Espanha e Brasil aparecem, dialeticamente, idênticos e diferentes, iguais e desiguais. Idênticos em termos gerais (com diferenças particulares) quanto à crise da habitação, quanto ao papel do Estado no favorecimento dessa dinâmica, quanto ao papel do endividamento familiar e da precarização da vida cotidiana dos habitantes para a realização desses processos globais. Iguais em relação à necessidade do capital de se remunerar ora aqui ora ali, de realizar as mais-valias globais ora mais na Europa ora mais na América Latina, e desiguais pois existem desigualdades históricas, de níveis de renda das famílias, de acesso a direitos, que pesam sobre as lutas contra esses processos.

Na Espanha, o Estado de Bem-estar social - "tímido" se comparado com outros Estados europeus, sobretudo com os países nórdicos - se atrofia, e com ele as classes médias, que em sua época foram centrais para a consolidação do Estado e para a reprodução capitalista. Um movimento teórico possível seria então pensar num processo mundial dialético de relativa e momentânea descapitalização das classes médias nos países avançados articulada a uma capitalização (certamente também momentânea) mais acentuada das frações inferiores das classes médias brasileiras, mais numerosas em massa do que aquilo que seria a classe média em si em nosso país. Este processo se realiza reproduzindo capital, produzindo a habitação (espaço) nas periferias metropolitanas e mantendo/aumentando as desigualdades existentes, desigualdades tanto internamente ao país (sem ascensão social dos novos moradores e com pouco crescimento econômico) quanto na escala mundial da relação entre os Estados-Nação.

Do ponto de vista de uma análise global e cíclica dos movimentos contraditórios do capitalismo, o Brasil apareceria como um dos lugares e momentos em que este processo pode e deve ocorrer. Assim, o momento de euforia e forte expansão por que tem passado o setor imobiliário da construção residencial no Brasil - sobretudo para as famílias em situação de rendimentos médios e baixos - pode estar integrando um novo patamar mundial de expropriação financeira, apoiado na expansão do crédito/endividamento das famílias brasileiras e sua integração maior ao mundo do consumo. $\mathrm{O}$ momento ascendente da economia imobiliário-financeira no Brasil contrasta com o 
de uma crise de sobre-endividamento ocorrida nos EUA e na Europa (sobretudo na Espanha), que acabou gerando uma forte crise habitacional nesses países e que nos adverte sobre os mecanismos e as capacidades expropriatórias do capital financeiro e da violência implícita nessa dinâmica.

Os mecanismos de financiamento imobiliário no Brasil têm sofrido alterações nos últimos anos, e apontam para um tipo de situação hoje vivida em Barcelona e na Espanha: o sobreendividamento das famílias. Com o agravante que o nível de renda no Brasil é bem menor que o das famílias espanholas. A Lei brasileira $N^{0}$ 9.514, de 20 de novembro 1997 (conhecida como Alienação Fiduciária de Imóveis) caminha no sentido de dar amplas e (quase) irrestritas garantias aos bancos em readquirir, sem complexos procedimentos judiciais, o imóvel do mutuário em dívida, aproximando-se com o sentido e o modelo de uma hipoteca. Dessa maneira, em Barcelona, a expropriação financeira das rendas das famílias tem culminado, cada vez mais e sobretudo para as frações médias desempregadas da população, num processo de expropriação fundiária, de perda de suas casas para bancos e caixas. No Brasil, são as frações populares e as frações inferiores das classes médias que têm sido alvo de uma rentabilização financeira via crédito habitacional e de políticas de governo - Minha Casa, Minha Vida - que têm sustentado os negócios imobiliários com a produção de "cubículos habitáveis" nas periferias, onde passam a viver famílias algumas das quais podem estar sendo temporariamente mantidas no jogo da propriedade até que uma nova e grande crise ocorra. Na Espanha, observou-se um processo de metropolização articulado à produção imobiliária residencial que tem realizado a expansão da expropriação financeira das famílias das classes médias, como se vê em Barcelona. Resta saber quais os rumos que este processo de metropolização apoiado na expansão do crédito habitacional irá seguir em nosso país, sendo necessário a tomada de ações contra futuras (prováveis) expropriações das frações inferiores das classes médias brasileiras de suas casas e de seus espaços cotidianos.

\section{REFERÊNCIA BIBLIOGRÁFICA}

ARANTES, O.; MARICATO, E.; VAINER, C. A cidade do pensamento único. Petrópolis-RJ: Vozes, 2002. BENACH, N.; TELLO i ROBIRA, R. En los intersticios de la renovación: estrategias de transformación del espacio y flujos de población en Barcelona. Revista de Geografía, Barcelona, n. 3. pp. 93-113, 2004.

BORJA, J.; MUXÍ, Z. (ed.). Urbanismo en el siglo XXI: Bilbao, Madrid, Valencia, Barcelona. 1a. ed.; 2a. reimpressão Barcelona: Edicions UPC; ETSAB, 2009.

BUSQUETS, J. Barcelona: la construcción urbanística de una ciudad compacta. Barcelona: Ediciones del Serbal, 2004.

CAPEL, H. Capitalismo y morfología urbana en España. Barcelona: Círculo Universidad, Estudio General, 1990.

CAPEL, H. El modelo Barcelona: un examen crítico. 2a. ed. Barcelona: Ediciones del Serbal, 2009.

CARLOS, A. F. A. A (Re)produção do Espaço Urbano. São Paulo: Edusp, 2008.

DELGADO, M. La ciudad mentirosa: fraude y miseria del 'modelo Barcelona'. Madrid: Los Libros de la Catarata, 2007.

FONT, A. Región urbana de Barcelona: de la ciudad compacta a los territorios metropolitanos. In: INDOVINA, F. (coord.). La ciudad de baja densidad: lógicas, gestión y contención. Barcelona: Diputació de Barcelona, 2007. (Colección Estudios; Serie Territorio n.1).

HALL, P. Cidades do amanhã. São Paulo: Perspectiva, 2002.

HARVEY, D. O novo imperialismo. São Paulo: Edições Loyola, 2004.

INDOVINA, F. (org.). La ciudad de baja densidad: lógicas, gestión y contención. Barcelona: Diputació de Barcelona, 2007. (Colección Estudios; Serie Territorio n. 1).

LEFEBVRE, H. Espaço e política. Belo Horizonte: Ed. UFMG, 2008.

LENCIONI, S. Uma nova determinação do urbano: o desenvolvimento do processo de metropolização do espaço. In: CARLOS, A. F. A.; LEMOS, A. I. G. (orgs.) Dilemas urbanos: novas abordagens sobre a cidade. 
São Paulo: Contexto, 2003.

LÓPEZ HERNÁNDEZ, I.; RODRÍGUEZ LÓPEZ, E. Fin de ciclo: financiarización, territorio y sociedad de propietarios en la onda larga del capitalismo hispano (1959-2010). Madrid: Traficante de Sueños, 2010. MARTÍNEZ PEINADO, J. Dossier de l'alumnat: crisi econòmica i escenaris de postcrisi. Material do curso de mesmo nome realizado na Universitat Barcelona, jul. 2010.

MUÑOZ, F. La producción residencial de baja densidad en la provincia de Barcelona (1985-2001). In: INDOVINA, F. (coord.). La ciudad de baja densidad: lógicas, gestión y contención. Barcelona: Diputació de Barcelona, 2007. (Colección Estudios; Serie Territorio n.1).

NAREDO, J. M. El modelo inmobiliario español y sus consecuencias. In: URBANISMO, DEMOCRACIA Y MERCADO: UNA EXPERIENCIA ESPAÑOLA (1970-2010), 2010, Paris. Colóquio. Paris: Institut d'Urbanisme de Paris, Université de Paris 12, Val-de-Marne, Escuela T.S. de Arquitectura de Madrid, Casa de Velásquez, 2010. Disponível em: <http://www.sinpermiso.info/articulos/ficheros/naredo.pdf $>$. Acesso em: 12 ago. 2010.

NELLO, O. Contra la dispersión, intensidad. Contra la segregación, ciudad. In: INDOVINA, F. (coord.). La ciudad de baja densidad: lógicas, gestión y contención. Barcelona: Diputació de Barcelona, 2007. (Colección Estudios; Serie Territorio n.1).

ROBIRA, R. T. Áreas metropolitanas: espaços colonizados. In: CARLOS, A. F. A.; CARRERAS, C. (orgs.). Urbanização e mundialização. São Paulo: Contexto, 2005.

SÁNCHEZ, J-E. et al. (org.). Barcelona: de ciudad industrial a metrópolis internacional. Barcelona: Grupo de Geografia Económica (AGE), Universitat de Barcelona, 2009. 